\title{
Reducing maternal and child mortality in Punjab: The untapped potential of family planning
}

\author{
Zeba Sathar \\ Population Council \\ Maqsood Sadiq \\ Seemin Ashfaq \\ Population Council
}

Follow this and additional works at: https://knowledgecommons.popcouncil.org/departments_sbsr-rh

Part of the Demography, Population, and Ecology Commons, Family, Life Course, and Society Commons, International Public Health Commons, Maternal and Child Health Commons, and the Women's Health Commons How does access to this work benefit you? Let us know!

\section{Recommended Citation}

Sathar, Zeba, Maqsood Sadiq, and Seemin Ashfaq. 2015. "Reducing maternal and child mortality in Punjab: The untapped potential of family planning," Policy brief. Islamabad: Population Council, The Evidence Project. 


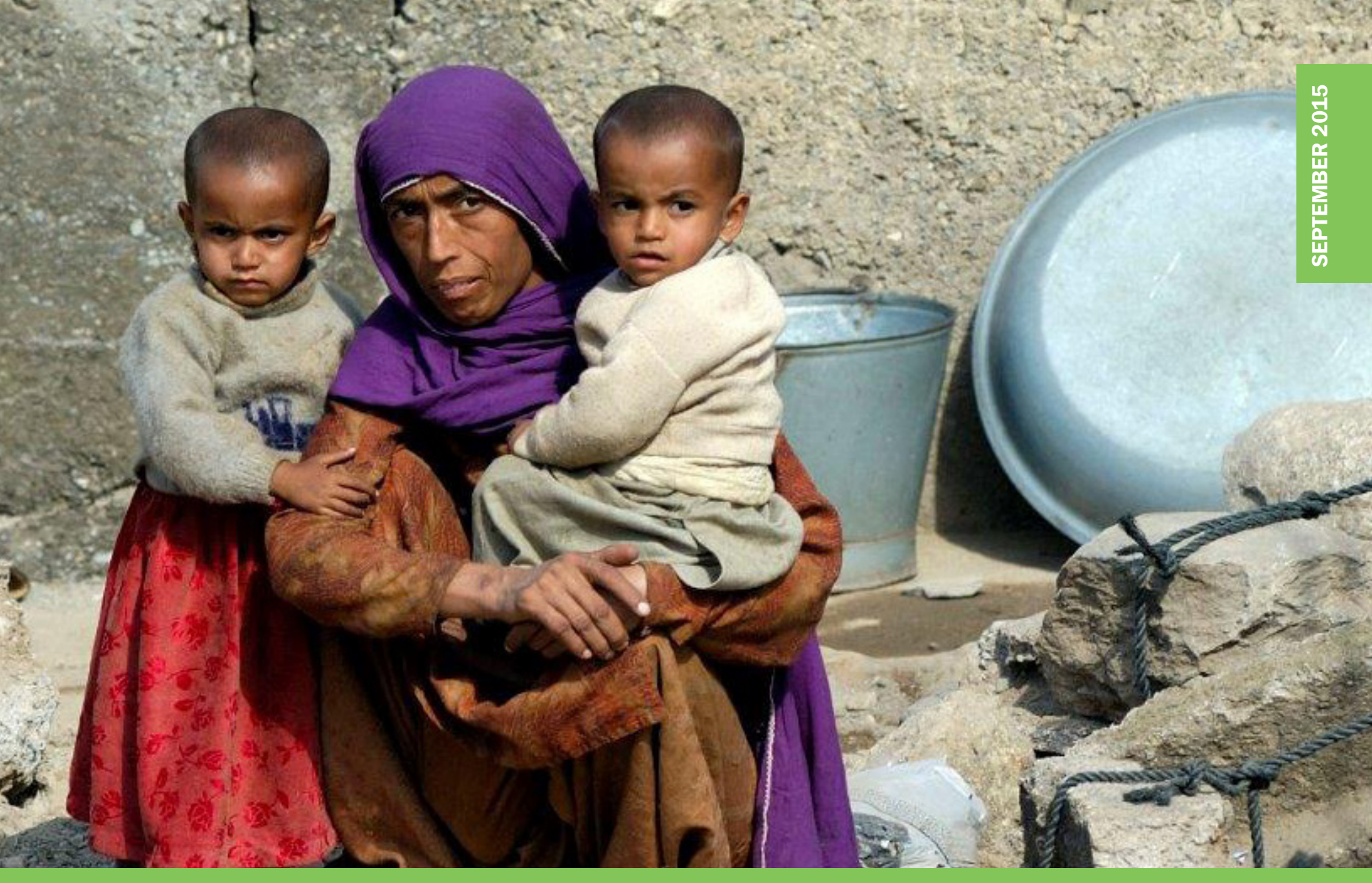

POLICY BRIEF

\section{REDUCING MATERNAL AND CHILD MORTALITY IN PUNJAB}

The Untapped Potential of Family Planning

Family planning is recognized as a necessary tool for faster fertility decline leading to accelerated economic development. However, its

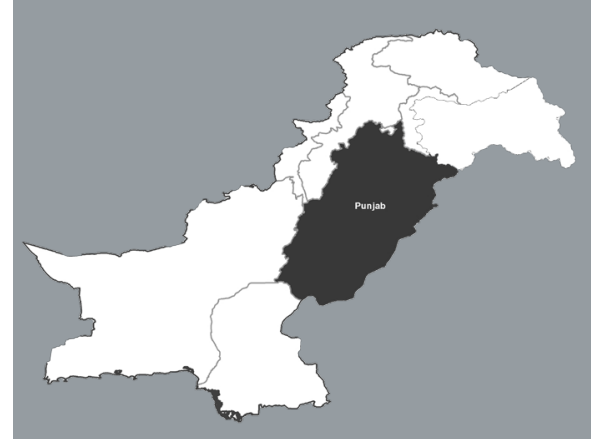
unique and potent role in preserving mother and child health is less well understood. This brief explains why family planning must be prioritized in Punjab's health strategy as a key intervention for reducing maternal, infant, and under-five mortality in the province. 


\section{RETHINKING THE ROLE OF FAMILY PLANNING IN PUNJAB'S HEALTH STRATEGY}

Punjab confronts a high incidence of preventable deaths among mothers, infants, and young children. Maternal deaths account for 16 percent of mortality among women of reproductive age (PDHS 2007). In 2012, the maternal mortality ratio (MMR) was estimated at 189 per 100,000 births (Sathar, Wazir and Sadiq 2014); the infant mortality ratio (IMR) was 88 per 1,000 births; and the under-five mortality ratio (U5MR) was 105 per 1,000 births (PDHS 2013). These ratios currently translate into an annual death toll of over 6,000 women, 280,000 infants and 54,000 children (aged 1-4), primarily due to conditions that could easily be prevented with basic healthcare.

Over the past 15 years, the health system's response to lowering maternal and child mortality has focused mainly on increasing women's access to antenatal and obstetric care, improving nutrition, expanding immunization, and ensuring treatment for the two major child killers, diarrhea and pneumonia. However, in the arsenal to improve maternal and child health $(\mathrm{MCH})$, family planning has been accorded a low role. The Punjab Growth Strategy 2018 recognizes population growth as a factor affecting economic growth, but makes no direct reference to family planning as a major intervention for addressing infant and maternal mortality (Government of Punjab 2015a). While efforts to increase contraceptive prevalence are under way, they are spearheaded by the Population Welfare Department, not the Department of Health. This administrative bifurcation reflects the view, held until recently by most policymakers, that family planning is a measure for limiting fertility and population growth rather than a core health intervention.

However, there is strong evidence to warrant a repositioning of family planning in national and provincial health strategies as a critical $\mathrm{MCH}$ tool (Box 1). It is internationally recognized that women face significantly heightened risks of pregnancy-related death when they are too young (less than 18 years) or too old (more than 34 years) at the time of birth; when the birth interval is less than 33 months; and when parity exceeds three children. In addition, every unintended pregnancy represents an unnecessary risk, which escalates when a woman resorts to induced abortion-especially when the procedure is performed in unsafe settings, as is typically the case in Pakistan.
BOX 1

IGNORED AT PERIL

Evidence for family planning's

massive potential to reduce

maternal and child mortality

It is estimated that between 1990 and 2010 , contraceptive use has accounted for about 40 percent of the reduction in maternal deaths in developing countries; if all the unmet need for contraception in the world were fulfilled, a further 30 percent reduction in maternal deaths would be achieved (Cleland et al. 2012). Moreover, voluntary family planning could eliminate the 13 percent of maternal deaths that occur due to unsafe abortions and 36 percent of maternal deaths caused by unintended pregnancies (Bongaarts et al. 2012).

In the specific case of Pakistan, Ahmed et al. (2012) estimate that family planning averted 42 percent of maternal deaths in 2008 (with a CPR of 29.2 percent).

Birth spacing has also been recognized as one of the strongest interventions to improve child survival rates. According to Rutstein (2008), birth intervals of 33 months would reduce the U5MR by 13 percent, and, in Pakistan, neonatal, infant, and child mortality are almost halved when birth intervals are 4 years or more, compared to when they are less than 2 years.

Furthermore, we now know that children's risk of dying in infancy or before the age of five is strongly correlated with the same high-risk fertility behaviors that endanger mothers' lives. The strong association between maternal health and infant survival, particularly for neonates, is the basis of the Healthy Spacing and Timing of Pregnancies (HSTP) initiative launched by the World Health Organization (WHO).

In recent years, important improvements in $\mathrm{MCH}$ indicators have been achieved in Punjab. Between 1990-91 and 201213 , it is estimated that skilled birth attendance rose from 16 to 52 percent, and the proportion of women receiving ante- 
FIGURE 1: CONTRACEPTIVE PREVALENCE IN PUNJAB (\%)

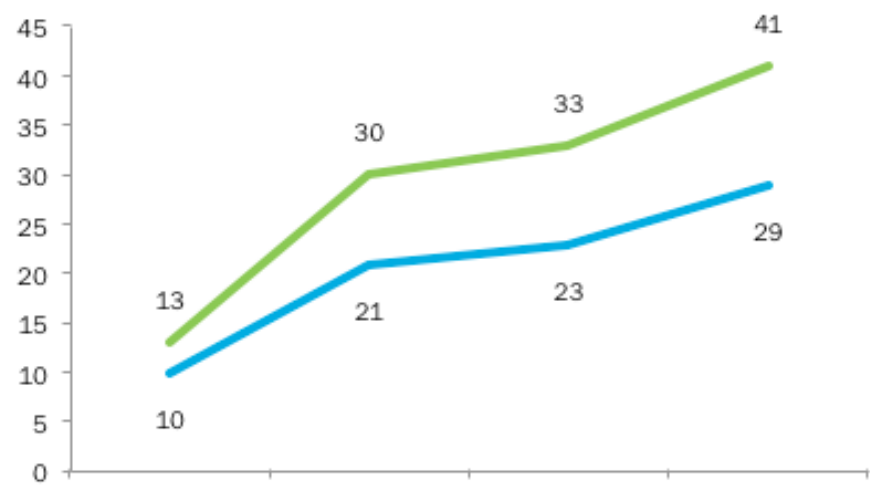

PDHS 1990-91 PRHFPS 2000-01 PDHS 2006-07 PDHS 2012-13

Any FP method $\longrightarrow$ Modern FP method

natal care went up from 22 to 78 percent (PDHS 1990-91 and 2012-13). Since 2001, complete immunization among children aged 12 to 23 months has also increased from 57 to 86 percent (PIHS/PSLM 2001-02 and 2013-14). However, over the past 15 years, a relatively low priority has been given to increasing the contraceptive prevalence rate (CPR), which inched forward by less than a percentage point a year from 30 percent in 2000-01 to only 41 percent in 2012-13 (Fig. 1).

To meet its ambitious MMR, IMR and U5MR targets, the government must leverage every promising intervention at its disposal. Family planning offers an extremely effective but as yet underutilized route for achieving huge reductions in maternal and child mortality.

Punjab's estimated MMR dropped steeply between 2001 and 2006, but the decline became much slower thereafter (Fig. 2). Similarly, the province's infant and child (under 5 years of age) mortality ratios were declining until 2006-07 but have since started to climb (Fig. 3). Regrettably, like the other provinces, Punjab was unable to achieve its Millennium Development Goals for MMR, IMR, and U5MR.

Encouragingly, a reduction in maternal and infant mortality has been declared a key nationwide priority under Vision
FIGURE 2: MATERNAL MORTALITY RATE IN PUNJAB TRENDS \& TARGETS

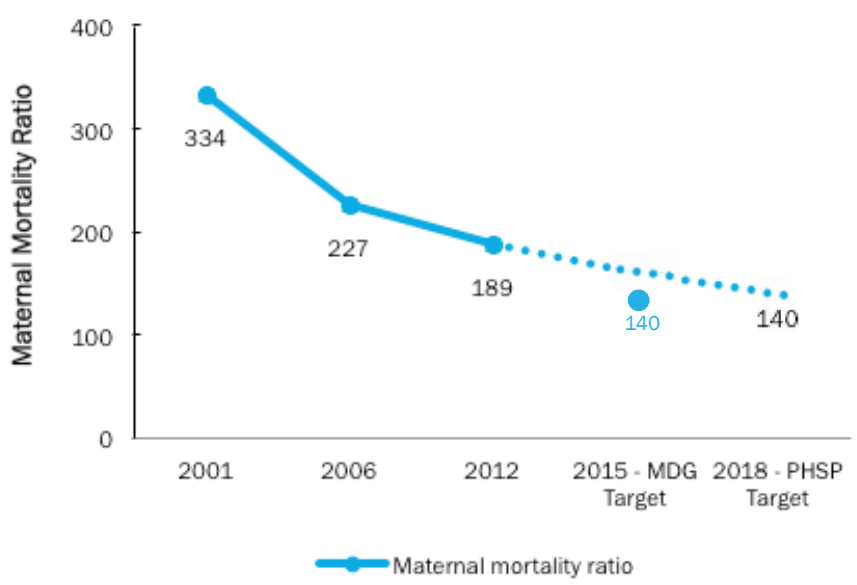

Note: Dotted as estimated/projected

Sources: PDHS 2013 and Punjab Health Sector Plan (PHSP) 2018.

FIGURE 3: INFANT AND UNDER-FIVE MORTALITY RATIO IN PUNJAB - TRENDS \& TARGETS

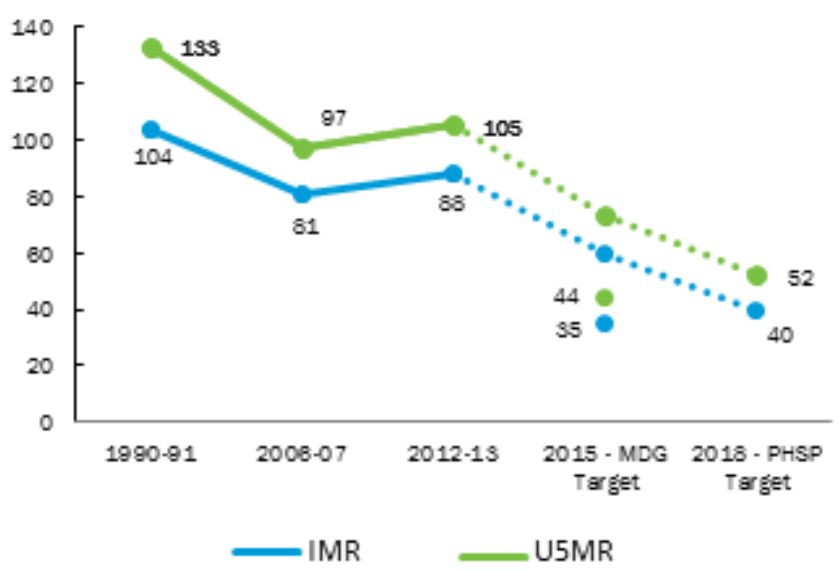

Note: Dotted as estimated/projected

Sources: PDHS 2013 and Punjab Health Sector Plan (PHSP) 2018.

2025, and the Government of Punjab has declared new targets for tackling this issue in the Punjab Health Sector Plan 2018 (Government of Punjab 2015b). By 2018, it aims to lower the MMR to 140 per 100,000 births, the IMR to 40 per 1,000, and the U5MR to 52. However, in order to meet these ambitious-and still distant-goals, the government will need to leverage every promising intervention at its disposal. Family planning offers an extremely effective but as yet untapped route for achieving the large mortality reductions required. 
IMPROVING MATERNAL AND

CHILD SURVIVAL IN PUNJAB THROUGH FAMILY PLANNING

Among men and women in Punjab, there is a growing preference for avoiding the high-risk fertility behaviors that threaten maternal and child health. It is estimated that 71 percent of women wish to limit or delay births by two years (Fig. 4), and this desire is shared by 65 percent of men (PDHS 2013).

FIGURE 4: FERTILITY PREFERENCES OF WOMEN IN PUNJAB (\%) 2012-2013

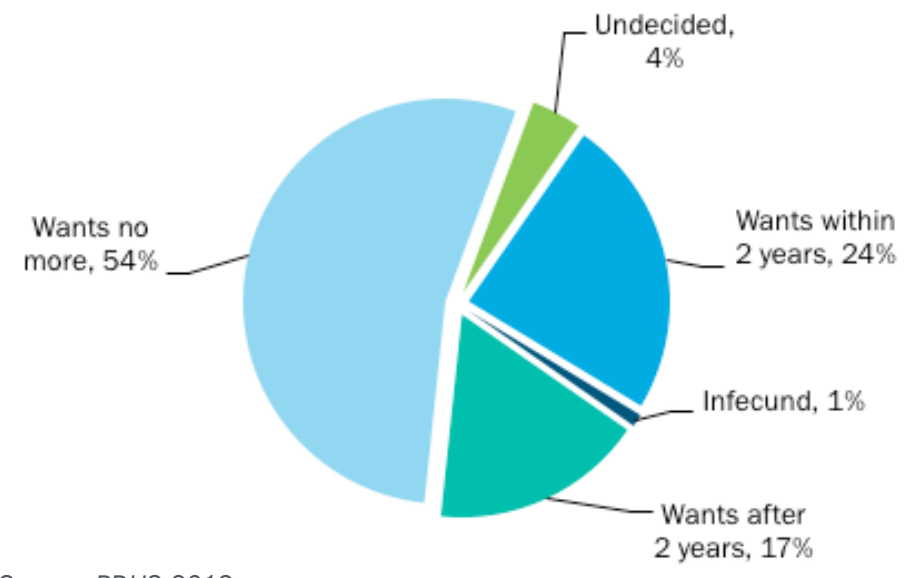

Source: PDHS 2013

\section{FIGURE 5: THE GAP BETWEEN FAMILY PLANNING DEMAND AND USE (\%)}

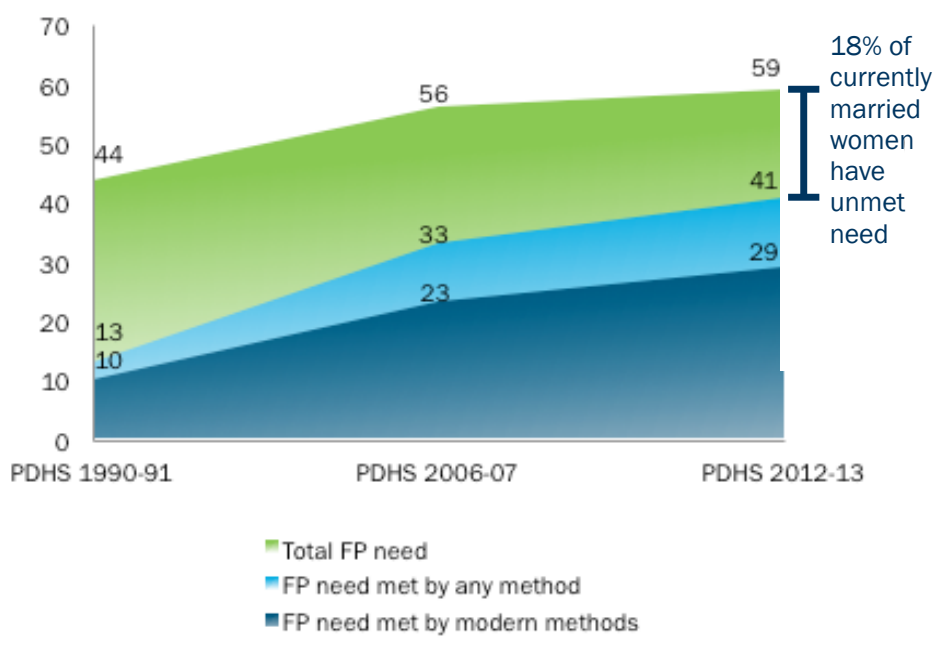

Worryingly, however, these healthier fertility preferences are not translating into practice. Surveys show that 59 percent of married women of reproductive age (MWRA) in Punjab would like to use contraceptives to space or limit births. However, only 41 percent are using any family planning method (Fig. 5). The proportion of women using reliable modern methods is even smaller, i.e., 29 percent. Therefore, nearly a third of family planning need in Punjab is currently unmet-18 percent of MWRA are not using any method, modern or traditional, even though they wish to space or limit births. This gap indicates that a significant increase in contraceptive prevalence can be achieved capitalizing on this group even without extensive demand generation efforts.

The gap between family planning demand and need also means, however, that a large proportion of MWRA in Punjab are unable to practice healthy spacing and timing of pregnancies, which exposes them and their young children to the following sources of mortality risks:

1. Unintended pregnancies - The province's total fertility rate (TFR) is 3.8 while the estimated average number of children wanted by women is 2.8 (PDHS 201213). About a third of the 4.7 million pregnancies that occur in the province every year are unintended and, on average, every woman of reproductive age faces the unnecessary risk and physical burden of one unintended pregnancy.

2. Unsafe induced abortions - Due to unwanted pregnancies, there were nearly 1.3 million induced abortions in Punjab in 2012, resulting in over 367,000 cases of post-abortion complications (PAC). With 16 out of every 1,000 women of reproductive age seeking treatment, the province accounted for 60 percent of the PAC caseload for the entire country (Population Council 2014).

3. Adolescent pregnancy - At the time of the 2012-13 PDHS, 7.4 percent of girls (aged 15-19) had begun childbearing. Among every 1,000 women in this age group, 21 had given birth in urban areas and 56 in rural areas. These young women face special health risks that are further aggravated by poverty and relatively lower access to $\mathrm{MCH}$ services. 
4. Infants of teenaged mothers - Moreover, as shown in Fig. 6, neonatal mortality among children of teenaged mothers is almost double the level found among women aged 20-29, although post-neonatal mortality ratios are nearly the same.

5. Late childbearing - According to PDHS 2013, some 12 percent of women in Punjab had given birth after the age of 35. Late childbearing is associated with heightened risks of maternal and infant health issues.

6. High parity - PDHS 2013 found that 46 percent of women in Punjab had given birth to four or more children. This situation exposes mothers as well as infants and young children to heightened risks of malnutrition and health complications.

7. Short birth intervals - To give mothers the best chance to maintain sound health while delivering and raising healthy children, WHO recommends an interval of at least 33 months between births. Birth spacing is also known to play an important role in the nutritional status of children under 5 years of age, with shorter birth intervals increasing the risk of low weight, at birth and beyond, as well as stunting. However, slightly over 40 percent of women in Punjab gave birth less than 24 months after a previous birth, while 71 percent gave birth less than 36 months after the previous birth (PDHS 2013). Fig. 7 illustrates the great differences in mortality ratios among infants born after short and adequate birth intervals.

The above-outlined risks, which lead to maternal, infant and young child mortality, can be addressed through family planning. To prevent the mortality associated with high-risk fertility behavior, the existing demand for family planning must be fulfilled at the earliest by eliminating current unmet need. In the longer run, the public must be educated about the necessity of healthy spacing and timing of pregnancies so that demand for contraception increases to cover the complete family planning needs of all MWRA. Increased use of family planning would not only prevent the mortality and sickness caused by high-risk fertility behavior, it would also reduce the pressure of unintended pregnancies and births, and associated maternal and child morbidity on the health system.

\section{FIGURE 6: NEONATAL AND POST-NEONATAL MORTALITY RATIOS IN PUNJAB BY MOTHERS' AGE AT BIRTH (DEATHS PER 1,000 LIVE BIRTHS)}

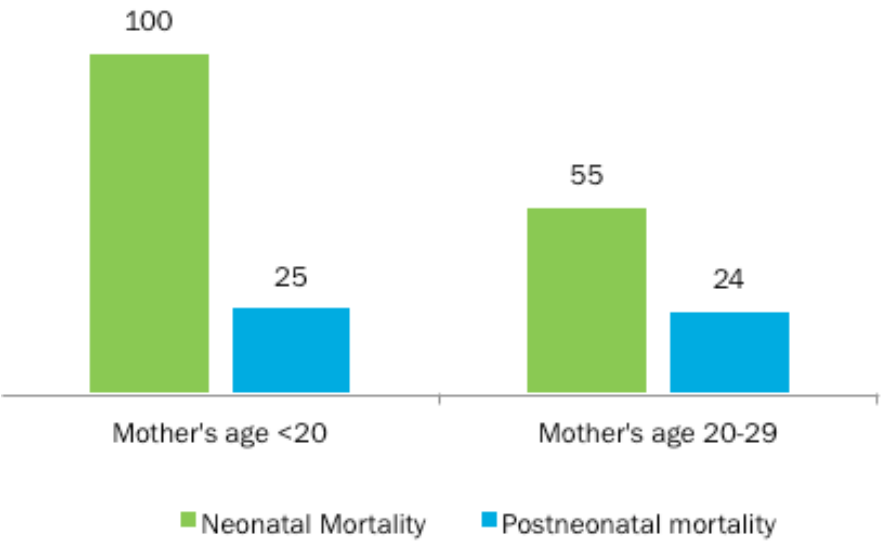

Source: PDHS 2013

FIGURE 7: NEONATAL AND POST-NEONATAL MORTALITY RATIOS IN PUNJAB BY BIRTH INTERVAL (DEATHS PER 1,000 LIVE BIRTHS)

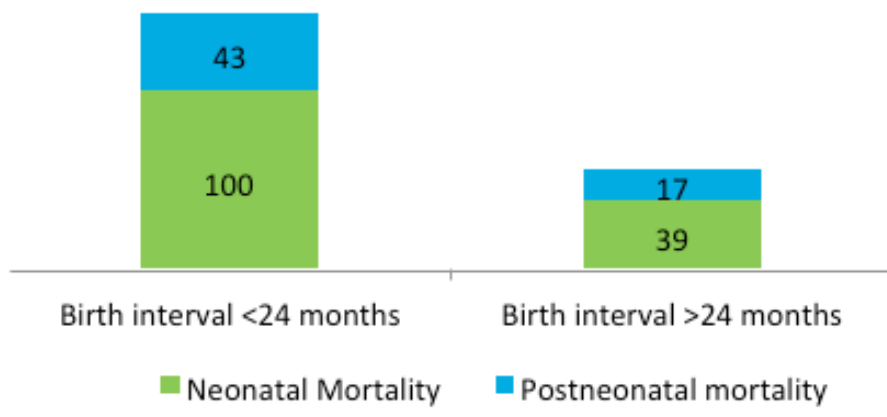

Source: PDHS 2013 
MEASURING THE POWERFUL LIFE-SAVING POTENTIAL OF FAMILY PLANNING IN PUNJAB

In 2014, the Population Council, Pakistan conducted a study to estimate the size of reductions achievable in maternal, infant, and child mortality in Punjab through increased family planning (Sathar, Wazir and Sadiq 2014). Simulations were conducted to gauge the change in maternal, infant and child mortality when existing unmet need for family planning (18 percent) is reduced or eliminated by raising the CPR.

In the case of maternal mortality, the study examined the effect of eliminating unmet need by raising the CPR from its existing level of 41 percent to 59 percent (Scenario 1 in Fig. 8). For comparison purposes, the effect of increasing skilled birth attendance from its present level of 52 percent to 80 percent was also examined (Scenario 2).

To measure the impact of family planning on infant and child mortality, simulations of two scenarios were conducted-one in which unmet need was reduced by raising the CPR to 50 percent (Scenario 1 in Figs. 9 and 10) and the second in which unmet need was completely eliminated by raising the CPR to 59 percent (Scenario 2).

The study arrived at the following eye-opening conclusions:

\section{Reduction Achievable in Maternal Mortality}

- Eliminating unmet need for family planning by raising the CPR to 59 percent would prevent 45 percent of maternal deaths (Fig. 8)

- Raising skilled birth attendance from 52 to 80 percent would prevent 33 percent of maternal deaths (Fig. 8)

- Eliminating unmet need and simultaneously increasing skilled birth attendance to 80 percent would prevent 63 percent of maternal deaths (Fig. 8)

\section{Reduction Achievable in Infant and Child Mortality}

- Reducing unmet need for family planning by increasing the CPR to 50 percent would reduce infant mortality by 14 percent (Fig. 9) and child (age 1-4) mortality by 35 percent (Fig. 10)

- Eliminating unmet need altogether would reduce infant mortality by 26 percent (Fig. 9) and child (age 1-4) mortality by 76 percent (Fig. 10).

These findings show that family planning programs should be an equally important component of improving maternal health and reducing maternal and child mortality. In fact, greater reductions in maternal mortality can be achieved by eliminating unmet need for family planning than by increasing skilled birth attendance.

FIGURE 8: MATERNAL LIVES THAT CAN BE SAVED ANNUALLY IN PUNJAB BY INCREASING CONTRACEPTIVE PREVALENCE AND SKILLED BIRTH ATTENDANCE

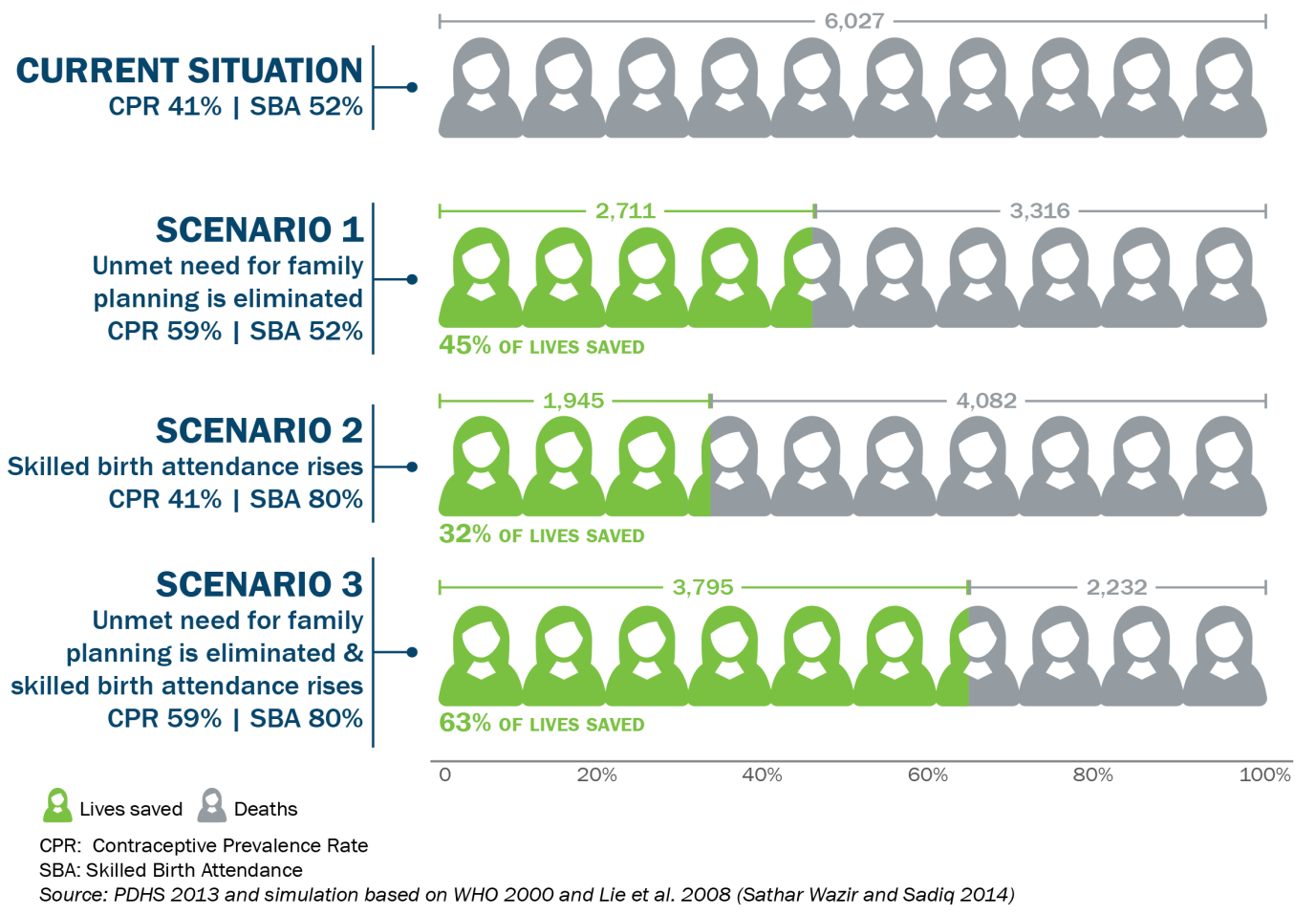


FIGURE 9: INFANT LIVES THAT CAN BE SAVED ANNUALLY IN PUNJAB BY INCREASING CONTRACEPTIVE PREVALENCE

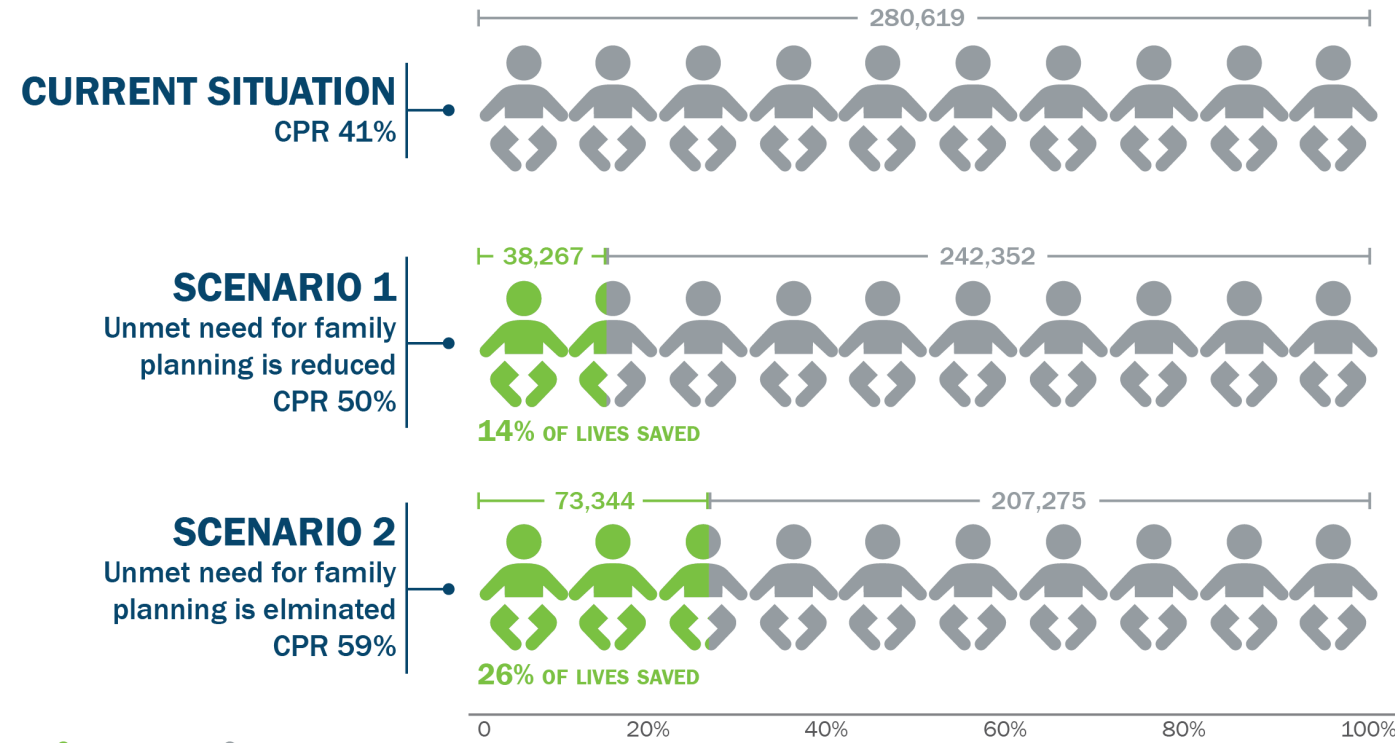

$\frac{1}{4}$ Lives saved $\frac{2}{8}$ Deaths

CPR: Contraceptive Prevalence Rate

Source: PDHS 2013 and simulation based on FAMPLAN model (Sathar Wazir and Sadiq 2014)

FIGURE 10: CHILD (AGED 1-4 YEARS) LIVES THAT CAN BE SAVED IN PUNJAB BY INCREASING CONTRACEPTIVE PREVALENCE
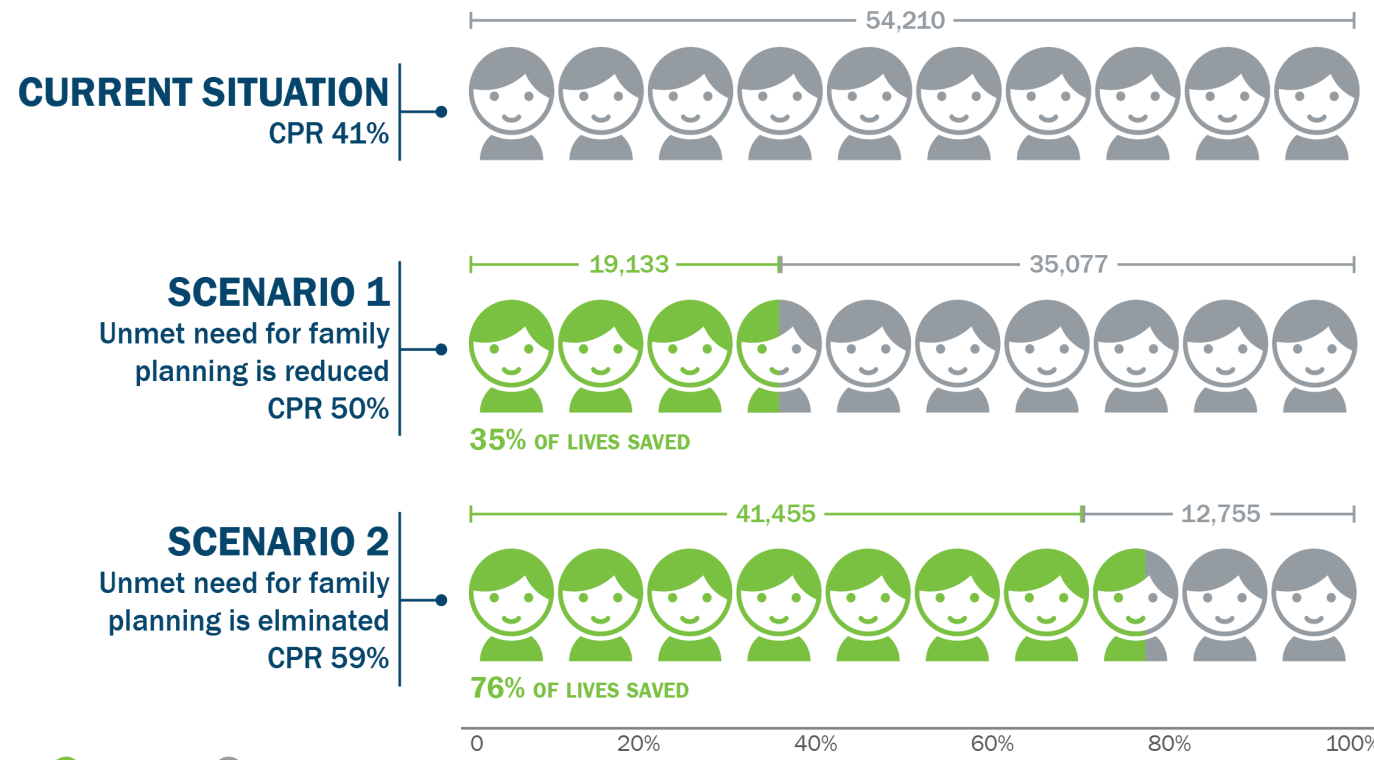

Lives saved Deaths

CPR: Contraceptive Prevalence Rate

Source: PDHS 2013 and simulation based on FAMPLAN model (Sathar Wazir and Sadiq 2014) 


\section{POLICY |MPLICATIONS}

For a rapid reduction in maternal, infant, and child mortality to the levels targeted for 2018 and onwards, the most effective strategies for improving $\mathrm{MCH}$ need to be galvanized in Punjab. Little attention has been paid to family planning in this context, but the evidence shows that it is one of the most powerful tools at the government's disposal. Simply by fulfilling the existing unmet need for birth spacing and limiting-which would mean raising the CPR to 59 percent-it is possible to prevent 45 percent of maternal deaths, 26 percent of infant deaths, and 76 percent of young child deaths. This will lead to proportionate declines in the maternal, infant, and child mortality ratios of the province. Notably, more women's lives can be saved in this manner than by increasing skilled birth attendance from 52 to 80 percent.

Family planning's wider health benefits further justify its immediate prioritization. These include, for example, reduced anemia among women; lower numbers of underweight, wasted, and stunted children; and reduced burden on antenatal, obstetric, postnatal and post-abortion services.

Moreover, family planning is highly cost-effective: every dollar spent on this intervention saves nearly four dollars that could otherwise be spent on maternal health, immunization, malaria, water and sanitation, and education (Bongaarts 2012).

In view of its strong health benefits, family planning must be swiftly repositioned in provincial policy as a key mother and child health intervention to be delivered with as much commitment, resources, and monitoring as other key $\mathrm{MCH}$ activities being pursued by the Department of Health. Issues of departmental ownership, management, and coordination must be quickly and thoughtfully resolved so all stakeholders can play optimal roles in striking at the root of maternal, infant, and child mortality in the province.
To ensure that family planning finds its due place in Punjab's development framework, it is also vital to recognize its profound links with the government's socioeconomic and population aims and policies. The benefits of family planning in terms of increased women's empowerment, female participation in the workforce, household savings, poverty reduction, and school enrollment are well-documented (Sathar, Wazir and Sadiq 2014). These gains will be most visible when interventions are targeted at the segments of Punjab with the greatest unmet need for family planning: the southern, western and eastern districts; the rural areas; poor communities; and young, uneducated women.

\section{REFERENCES}

Ahmed, S., Li, Q., F., Liu, L., \& Tsui, A. 2012. Maternal deaths averted by contraceptive use: An analysis of 172 countries. The Lancet, 380, 111-125.

Cleland, J., Conde-Agudelo, A., Peterson, H., Ross, J., \& Tsui, A. 2012. Contraception and health. The Lancet, 380, 149-156.

Government of Punjab. 2015a. Punjab Growth Strategy 2018: Accelerating Economic Growth and Improving Social Outcomes.

Government of Punjab. 2015b. Punjab Health Sector Plan 2018: Building a Healthier Punjab.

* Government of Punjab. 2014. Punjab Population Policy for Development: Directions and Leadership (Draft).

Government of Punjab. 2011. Multiple Indicator Cluster Survey, Punjab, 2011.

National Institute of Population Studies (NIPS) [Pakistan] and ICF International. 2013. Pakistan Demographic and Health Survey 2012-13. Islamabad, Pakistan, and Calverton, Maryland, USA: NIPS and ICF International.

Pakistan Bureau of Statistics. 2002. Pakistan Integrated Household Survey (PIHS) 2001-02. Statistics Division, Government of Pakistan, Islamabad.

Pakistan Bureau of Statistics. 2014. Pakistan Social \& Living Standards Measurement Survey (PSLM) 2013-14. Statistics Division, Government of Pakistan, Islamabad.

Punjab Health Sector Reforms Programme (PHSRP), Government of Punjab. 2012. Health Sector Strategy 2012-2020.

Population Council. 2014. Induced Abortions and Unintended Pregnancies in Pakistan, 2012. Islamabad.

Rutstein, S. 0. 2008. Further evidence of the effects of preceding intervals on neonatal, infant and under-five-years mortality and nutritional status in developing countries: Evidence from demographic and health surveys (Demographic and Health Surveys Working Paper No, 41). Calverton, MD: Macro International Inc.

Sathar Z.A., Wazir, M.A., and Sadiq, M. 2014. Prioritizing family planning for achieving provincial maternal child health and development goals. Islamabad: Population Council.

WHO. 2000. Maternal Mortality 2000: Estimates developed by WHO, UNICEF and UNFPA. Retrieved from http://whqlibdoc.who.int/publications/2004/9241562706.pdf?ua=1 (accessed March 2014).

\section{THE EVIDENCE PROJECT}

Population Council House No. 7, Street No. 62 Section F-6/3 Islamabad, Pakistan tel +92518445566 evidenceproject.popcouncil.org

CONTRIBUTORS

Dr. Zeba A Sathar (T.I.) Maqsood Sadiq Seemin Ashfaq
The Evidence Project is made possible by the generous support of the American people through the United States Agency for International Development (USAID) under the terms of cooperative agreement no. AID-OAA-A-13-00087. The contents of this document are the sole responsibility of the Evidence Project and Population Council and do not necessarily reflect the views of USAID or the United States Government.

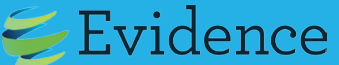

The Evidence Project uses implementation science-the strategic generation, translation, and use of evidence--to strengthen and scale up family planning and reproductive health programs to reduce unintended pregnancies worldwide. The Evidence Project is led by the Population Council in partnership with INDEPTH Network, International Planned Parenthood Federation, Management Sciences for Health, PATH, Population Reference Bureau, and a University Research Network.

(c) 2015 The Population Council, Inc.

Suggested Citation: Sathar, Zeba A., Maqsood Sadiq, and Seemin Ashfaq. “Reducing maternal and child mortality in Punjab: The untapped potential of family planning," Policy Brief. Islamabad, Pakistan: Population Council, Evidence Project 2015. 